\title{
ORIGINAL ARTICLE Reference values of bone stiffness index and C-terminal telopeptide in healthy European children
}

\author{
D Herrmann ${ }^{1}$, T Intemann ${ }^{1}$, F Lauria ${ }^{2}$, S Mårild ${ }^{3}$, D Molnár ${ }^{4}$, LA Moreno ${ }^{5}$, I Sioen ${ }^{6}$, M Tornaritis ${ }^{7}$, T Veidebaum ${ }^{8}$, I Pigeot L $^{1,9}$ \\ and W Ahrens ${ }^{1,9}$ on behalf of the IDEFICS consortium
}

BACKGROUND/OBJECTIVE: Quantitative ultrasound measurements and bone metabolic markers can help to monitor bone health and to detect impaired skeletal development. Population-based reference values for children may serve as a basis for preventive measures to reduce the risk of osteoporosis and osteoporotic fractures in later life. This is the first paper providing age-, sex- and height-specific reference values for bone stiffness index (SI) and serum carboxy-terminal cross-linking telopeptide of type I collagen (CTX) in healthy, apparently prepubertal children.

SUBJECTS/METHODS: In the population-based IDEFICS baseline survey (2007-2008) and follow-up (2009-2010), 18745 children from eight European countries were newly recruited. A total of 10791 2-10.9-year-old and 1646 3-8.9-year-old healthy children provided data on SI of the right and left calcaneus and serum CTX, respectively. Furthermore, height and weight were measured. Percentile curves were calculated using the General Additive Model for Location Scale and Shape (GAMLSS) to model the distribution of SI and CTX depending on multiple covariates while accounting for dispersion, skewness, and the kurtosis of this distribution.

RESULTS: SI was negatively associated with age and height in children aged 2-5 years, whereas a positive association was observed in children aged 6-10 years. The dip in SI occurred at older age for higher SI percentiles and was observed earlier in taller children than in smaller children. The CTX reference curves showed a linear-positive association with age and height. No major sex differences were observed for the SI and CTX reference values.

CONCLUSION: These reference data lay the ground to evaluate bone growth and metabolism in prepubertal children in epidemiological and clinical settings. They may also inform clinical practice to monitor skeletal development and to assess adverse drug reactions during medical treatments.

International Journal of Obesity (2014) 38, S76-S85; doi:10.1038/ijo.2014.138

\section{INTRODUCTION}

Unhealthy lifestyle habits, like physical inactivity may hamper the child attaining its genetically programmed peak bone mass. Moreover, an impaired skeletal development in early life can be caused by an underlying genetically or lifestyle-related disorder, for example, adiposity as well as by certain medical treatments. ${ }^{1-4}$ This may in return increase the risk of osteoporosis and osteoporotic fractures later in life. ${ }^{5-7}$ Previous studies reported that children having a low bone mineral density in prepuberty remain to have a low bone mineral density in adolescence. ${ }^{8-10}$ In contrast, other studies showed that an impaired skeletal development during childhood may be largely reversible when treating underlying diseases. ${ }^{11-13}$

Age- and sex-specific bone reference values can help to assess skeletal development during childhood and to compare the bone health status of a child with that of a healthy population having the same age, sex and ethnicity. Thus, deviations from a normal skeletal development may be identified in an early stage. Until now, paediatric reference data have mainly been used for diagnosing poor bone acquisition in children who are suffering from multiple fractures, diseases or receiving medical treatments affecting bone metabolism. ${ }^{11,14}$ Bone reference data may be not only a diagnostic tool for children with bone diseases ${ }^{15}$ but may also serve to monitor apparently healthy subjects and to identify those who may benefit from specific interventions to improve bone health.

Only few studies established paediatric reference values for physical bone measurements. Reference values are mainly reported for bone mineral content and areal bone mineral density (aBMD) assessed with dual-energy X-ray absorptiometry (DXA). These reference data are mostly based on Asian, mixed American and Caucasian populations and are predominantly available for children above the age of 6 years. ${ }^{10,14,16-21}$ Several studies reported limitations of DXA to assess bone status in growing individuals. Especially, the use of aBMD results in an artificial underestimation of the bone status in short people and an overestimation in tall people due to its areal but not volumetric measurement. This measure is size dependant owing to its twodimensional image projection of a three-dimensional structure. That is, it does not account for depth or size and hence, it is not able to predict the 'true density' of the bone. ${ }^{16,22}$ Furthermore, DXA does not distinguish between trabecular and cortical bone. It provides only little information on bone geometry and trabecular microarchitecture. Moreover, there is no evidence that aBMD is predictive for fracture risk in children. ${ }^{23}$

${ }^{1}$ Leibniz Institute for Prevention Research and Epidemiology-BIPS, Bremen, Germany; ${ }^{2}$ Unit of Epidemiology and Population Genetics, Institute of Food Sciences, Consiglio Nazionale delle Ricerche, Avellino, Italy; ${ }^{3}$ Department of Pediatrics, Institute of Clinical Sciences, The Queen Silvia Children's Hospital, Sahlgrenska Academy at University of Gothenburg, Gothenburg, Sweden; ${ }^{4}$ Department of Pediatrics, University of Pécs, Pécs, Hungary; ${ }^{5}$ GENUD (Growth, Exercise, Nutrition and Development) Research Group, University of Zaragoza, Zaragoza, Spain; ${ }^{6}$ Department of Public Health, Ghent University, Ghent, Belgium; ${ }^{7}$ Research and Education Institute of Child Health, Strovolos, Cyprus; ${ }^{8}$ Department of Chronic Diseases, National Institute for Health Development, Estonian Centre of Behavioral and Health Sciences, Tallinn, Estonia and ${ }^{9}$ Institute of Statistics, Faculty of Mathematics and Computer Science, Bremen University, Bremen, Germany. Correspondence: Professor Dr W Ahrens, Leibniz Institute for Prevention Research and Epidemiology-BIPS, Achterstr. 30, D-28359 Bremen, Germany.

E-mail: ahrens@bips.uni-bremen.de 
Quantitative ultrasound (QUS) may be a more appropriate method to monitor skeletal development in children compared to DXA. QUS is a quick, cost-efficient and radiation-free method to evaluate bone stiffness that indicates density, structure and composition of the bone. ${ }^{24,25}$ Especially, the calcaneus was found to be a reliable location to assess bone status. The calcaneus consists of $90 \%$ trabecular bone that shows a high metabolic rate. The bone microarchitecture is similar to that of the lumbar spine and the femoral neck, which are major body sites for diagnosing osteoporosis. $^{24}$ Besides the difference between QUS and DXA measurements assessing bone status, bone stiffness showed good correlations with aBMD assessed by DXA in adults ${ }^{25}$ and children. $^{26,27}$ Furthermore, it revealed to be highly prognostic with regard to bone fractures in adults ${ }^{28}$ and proved to be a valid measure for the risk for osteopenia in young patients. ${ }^{27}$ Up to now, QUS references were established mainly for adults but are barely available for children and adolescents. ${ }^{20,24}$

According to the recommendation of the International Society for Clinical Densitometry, a combined assessment of physical measures and biochemical bone metabolic markers is useful to identify a reduced skeletal development in children. ${ }^{11,15,29}$ Physical bone measurements predict the actual bone status. Bone metabolic markers, such as osteocalcin or collagen cross-linked telopeptides indicate reduced or increased bone turnover processes. These clinical parameters may be useful to monitor skeletal development, as they can be repeated at much shorter intervals. Hence, they allow detection of acute effects caused by diseases or treatments long time before changes in bone mass occur. ${ }^{15}$ Reference data on these bone metabolic markers are rare in children and are mostly limited to selected clinical populations with a limited age range. ${ }^{11,15,30,31}$

In the IDEFICS (Identification and prevention of Dietary- and lifestyle-induced health Effects in Children and InfantS) study, bone stiffness index (SI) was measured using QUS in a large European child cohort. Serum carboxy-terminal cross-linking telopeptide of type I collagen ( $\beta$-CrossLaps, CTX) as an indicator for bone resorption and bone turnover was measured in a case-control subsample.

The aim of the present study was to provide age- and sexspecific reference values for SI and CTX adjusted for body size for apparently prepubertal children based on an European sample of 18745 healthy children who participated in the IDEFICS study. To calculate reference values and percentile curves, the General Additive Model for Location Scale and Shape (GAMLSS) was used to model the distribution of SI and CTX depending on multiple covariates while accounting for dispersion, skewness, and particularly the kurtosis of this distribution. ${ }^{32,33}$

\section{MATERIALS AND METHODS}

Analysis group

In the population-based IDEFICS baseline survey (2007-2008, $T_{0}$ ) and follow-up (2009-2010, $T_{1}$ ) 18745 children aged 2-10.9 from eight European countries (Belgium, Cyprus, Estonia, Germany, Hungary, Italy, Spain, Sweden) were newly recruited and examined. The IDEFICS study is one of the current largest prospective European child cohorts. ${ }^{34}$ Besides the comprehensive IDEFICS examination programme, heel QUS was applied in a subsample.

Written informed consent was obtained from the parents and each child was asked to give verbal assent immediately before examination. Participants were free to omit specific modules like blood drawing. In each country, the participating centres obtained ethical approval by their responsible authority. The whole examination programme of the IDEFICS study as well as further information regarding the study design were recently described in detail. ${ }^{34-36}$

Figure 1 summarises all exclusion criteria as well as the number of included and excluded children of the final SI analysis group. A total of 11414 children having their first QUS measurement in $T_{0}(N=7539)$ or having no QUS in $T_{0}$ but in $T_{1}(N=2714)$ as well as all newly recruited children with QUS measurement in $T_{1}(N=1161)$ were considered for the current analysis. Thirty-three children from $T_{0}$ having no QUS in $T_{0}$ but in $T_{1}$ had an age above 10.9 years at $T_{1}$ and were therefore excluded from the present analysis.

We conducted a small reliability study based on five of eight Achilles devices that were used within the IDEFICS study to investigate measurement errors and outliers of SI values. QUS measurements were performed in 91 subjects and repeated three times per foot and device. Accounting for repeated measurements, a multilevel regression was performed, but showed no differences in SI values between the three repeated measurements and between measurements at the left and right foot. However, a significant deviation of the SI values between the devices was observed varying within a range of $0-5 \mathrm{SI}$ units on average. A significant discrepancy between the devices was also found for the absolute SI difference of the left and right foot. Based on these results, the 97th percentile of the absolute difference between the SI values of the right and left foot was considered to reflect unreliable measurements. According to this quality criterion, 341 children were excluded from the present analysis. Decreased birth weight associated with premature birth and growth retardation causes reduced bone accretion. Hence, 14 children with a birth weight $<1000 \mathrm{~g}$ were excluded according to the ICD-10 criterion on 'extremely low birth weight'. ${ }^{37,38}$ Moreover, diseases and medical treatments that directly affect bone metabolism were identified by a health and medical history questionnaire. Diseases and treatments were categorized according to the ICD-10 and ATC coding, respectively (see Table 1). ${ }^{37,39}$ We excluded 111 children with a disease and 115 children receiving medical treatments that directly impair bone metabolism. ${ }^{5,15}$ Finally, nine children were excluded because their measurement values exceeded five s.d. values of the age- and sex-specific height $z$-score according to International Obesity Task Force. ${ }^{40}$ Thus, the final analysis group consisted of 10791 children for SI (see Figure 1).

Besides other bone metabolic markers, serum CTX has been analysed in a subsample drawn from the IDEFICS cohort for a case-control study. SI was chosen as an indicator for bone health. Within this case-control study, children between 2 and 9.9 years who had an SI below the 15th age- and sex-specific percentile of all IDEFICS children were eligible and classified as cases having low SI. Controls were randomly selected from the remaining cohort and matched to cases by age, sex and study centre. A total of 1646 children aged 3.0-8.9 years provided sufficient data on CTX and SI and were considered for the CTX analysis group, applying the same exclusion criteria as for the SI analysis group (see Table 1 and Figure 2).

\section{Measurements}

QUS (Lunar Achilles Insight, GE Healthcare, Milwaukee, WI, USA) ${ }^{41}$ was used to measure SI on the right and left foot. Both measurements were used to calculate the mean, which was considered for calculating the present reference values. In a subsample, the raw QUS measurements broadband ultrasound attenuation and speed of sound were measured. Reference values of these parameters will be considered in further publications. For standardised measurements, the child was asked to sit barefoot on a stable chair directly in front of the device. The leg was positioned so that the foot and calf were aligned with the foot positioner. The foot was positioned using an adapter for children's feet to put the calcaneus in focus. The study nurse made sure that the foot was flat and positioned firmly against the bottom of the footplate and that the child was not moving during the measurement. When changing the measured foot, the position on the chair had to be adjusted. Quality control was performed weekly, using the implemented quality assurance test of Achilles Insight. ${ }^{41}$

For laboratory analysis of CTX, blood samples were drawn in the morning (between 8 a.m. and 10 a.m.) after an overnight fast. Blood samples were centrifuged $(2100 \mathrm{~g}, 10 \mathrm{~min}$, room temperature) within $2 \mathrm{~h}$ of venipuncture, frozen within about $4 \mathrm{~h}$ after withdrawal and stored at $-80^{\circ} \mathrm{C}$. Serum CTX $\left(\mathrm{ng} \mathrm{ml}^{-1}\right)$ was determined by electrochemiluminescence assay using Roche, ECLIA Modular E17 (Roche, Diagnostics, Mannheim, Germany).

Body height (Seca 225 stadiometer, seca, Birmingham, UK) and body weight (Tanita BC 420 SMA, Tanita Europe, Sindelfingen, Germany) were measured to the nearest $0.1 \mathrm{~cm}$ and $0.1 \mathrm{~kg}$, respectively. Body mass index $\left(\mathrm{kg} \mathrm{m}^{-2}\right)$ as well as $z$-scores of height, weight and body mass index were calculated according to the British 1990 growth reference. ${ }^{40}$ Moreover, children were categorised as thin (grade 1-3), normal weight, overweight and obese using the International Obesity Task Force criteria. ${ }^{42}$ Leg-to-leg bioelectrical impedance was measured with the Tanita scale and used to calculate fat-free mass based on the Tyrrell formula. ${ }^{43}$ fat-free mass index $\left(\mathrm{kg} \mathrm{m}^{-2}\right)$ was calculated according to Wells and Cole. ${ }^{44}$ 


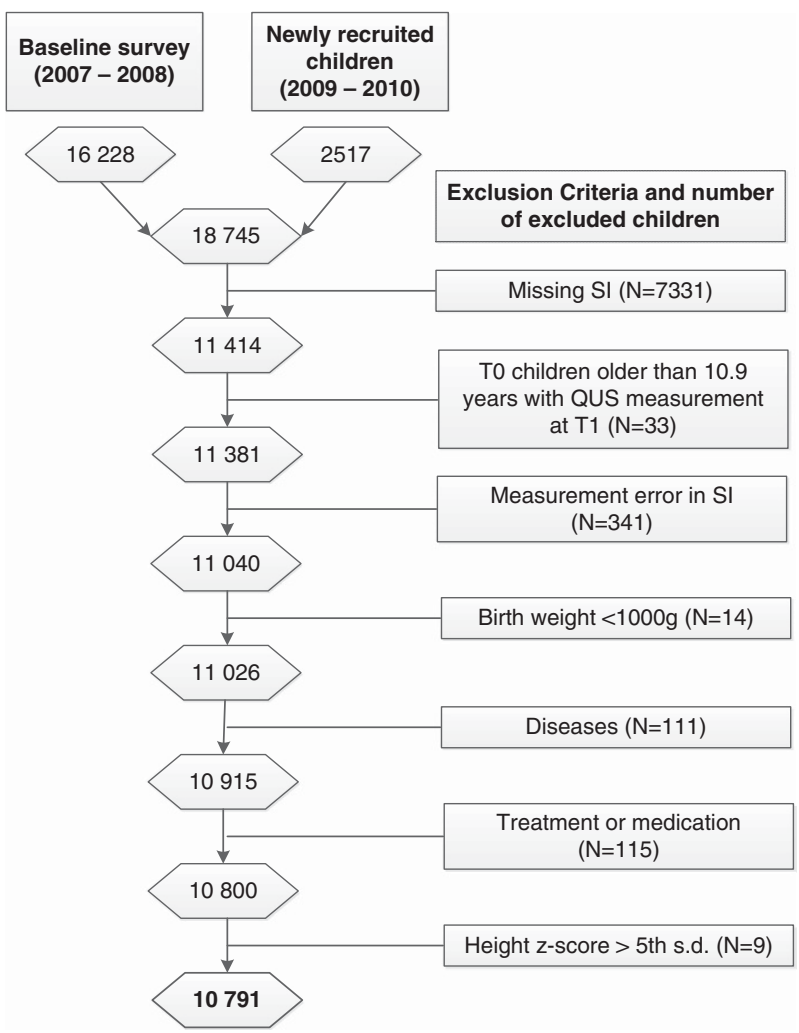

Figure 1. Number of included and excluded children per exclusion criteria for the SI analysis group from the IDEFICS population.

\section{Statistical analyses}

For both analysis groups, mean and s.d. of SI and CTX as well as of age, height and weight of 1-year age groups were calculated to describe study characteristics. In particular, percentile values of SI and CTX were calculated as a function of different covariates, for example, age, height or weight, stratified by sex using the GAMLSS method.

Due to the case-control design, the CTX sample included a high percentage $(50 \%)$ of cases with a low SI that was defined below the 15th age- and sex-specific SI percentiles. To correct the GAMLSS analyses for oversampling of cases against controls, we used weights for cases and controls in the GAMLSS models calculating percentile values for CTX. These weights were based on the original distribution in the study sample (cases: $15 \%$; controls: $85 \%$ ).

The GAMLSS method is an extension of the LMS method that models three parameters depending on one explanatory variable: $(M)$ accounts for the median of the outcome variable and the coefficient of variation; (S) accounts for the variation around the mean and adjusts for non-uniform dispersion, while the skewness (L) accounts for the deviation from a normal distribution using a Box-Cox transformation. The GAMLSS method is able to consider distributions with varying kurtosis and multiple covariates in the model. We used the gam/ss package (version 4.2-6) of the statistical software $\mathrm{R}$ (version 3.0.1). ${ }^{45}$ Different distributions, that is, the Box-Cox power exponential, the Box-Cox transformation or the Box-Cox Cole and Green distribution were fitted to the observed distribution of SI. The normal, the power exponential and the $t$-family distribution were fitted to the observed and weighted distribution of CTX.

Depending on the potential covariates (for example, age, height, height $z$-score, weight, weight $z$-score, body mass index, body mass index $z$-score and fat-free mass index), distribution parameters were modelled either as a constant, as a linear function or as a cubic spline. To identify the best combination of these covariates, different combinations were investigated to choose the best model. Goodness of fit for both dependant variables $\mathrm{SI}$ and CTX was assessed based on the Bayesian Information Criterion, Q-Q plots and worm plots. ${ }^{46}$ The best model for SI and CTX included the covariates, age and height. For modelling SI percentiles, no adjustment for kurtosis was needed. Therefore, the final SI model for both sexes considered a Box-Cox Cole and Green distribution modelling $\mu$ as a linear
Table 1. Frequency of excluded disorders and medical treatments for establishing the $\mathrm{SI}$ and $\mathrm{CTX}$ analysis group

\begin{tabular}{|c|c|c|}
\hline & $\begin{array}{c}\text { Excluded } \\
\text { children (N) } \\
\text { for } S I\end{array}$ & $\begin{array}{l}\text { Excluded } \\
\text { children (N) } \\
\text { for CTX }\end{array}$ \\
\hline \multicolumn{3}{|l|}{ Disease } \\
\hline Cancer & 13 & 2 \\
\hline Disorders of thyroid gland & 13 & 1 \\
\hline $\begin{array}{l}\text { Endocrine disorders (for example, lack } \\
\text { of growth hormone) }\end{array}$ & 8 & - \\
\hline $\begin{array}{l}\text { Vitamin D deficiency /rickets } \\
\text { /osteomalacia }\end{array}$ & 1 & - \\
\hline Dietary calcium deficiency & 1 & - \\
\hline Cerebral palsy & 12 & 2 \\
\hline Hemiplegia & 1 & - \\
\hline Rheumatic fever & 6 & 1 \\
\hline Disorders of arteries and arterioles & 6 & 2 \\
\hline Renal failure/disease of kidneys & 3 & - \\
\hline $\begin{array}{l}\text { Diseases of the musculoskeletal } \\
\text { system }\end{array}$ & 5 & 1 \\
\hline Osteochondrodysplasias & 1 & - \\
\hline $\begin{array}{l}\text { Fractures/disorders of continuity } \\
\text { of bone }\end{array}$ & 34 & 5 \\
\hline Osteomyelitis & 4 & 1 \\
\hline $\begin{array}{l}\text { Other disorders of bone (for example, } \\
\text { osteonecrosis, Paget disease) }\end{array}$ & 3 & - \\
\hline Sum & 111 & 15 \\
\hline \multicolumn{3}{|l|}{ Medication and Treatments } \\
\hline Chemotherapeutics & 5 & 1 \\
\hline Corticosteroids & 106 & 9 \\
\hline Sex hormones & 1 & 1 \\
\hline $\begin{array}{l}\text { Pituitary and hypothalamic hormones } \\
\text { and analogues }\end{array}$ & 2 & - \\
\hline Tetracyclines & 1 & 1 \\
\hline Sum & 115 & 12 \\
\hline
\end{tabular}

function of age and a cubic spline of height, $\log (\sigma)$ and $v$ as cubic splines of height only. The final model for CTX considered a normal distribution modelling $\mu$ as a linear function of age and height and $\log (\sigma)$ as constant in both sexes. Figure 3, in which the Q-Q plots of residuals for SI and CTX in boys are depicted, shows that the derived percentiles fit the data well. The same was observed for girls (data not shown).

Final models of SI and CTX were used to calculate percentile values for

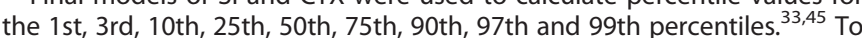
present values of the calculated percentiles, tables were presented for 1-year age groups and seven height percentiles (3rd, 10th, 25th, 50th, 75th, 90th and 97th). Further age- and sex-specific reference values of the 5th, 15th, 85th and 95th percentiles of SI and CTX will be provided in (Supplementary Tables A-D). In the following, children aged $2-<6$ years and $6-<11$ years will be referred to as preschool and primary school children, respectively.

\section{RESULTS}

Characteristics of the analysis groups for SI and CTX

Tables 2 and 3 present the sex-specific characteristics of the SI and CTX analysis groups, stratified by 1-year age groups, respectively. The SI analysis group included children aged 2-10.9 years and consisted of 5412 boys and 5379 girls. Boys and girls had similar average SI values. Although, preschool girls tended to have slightly higher SI values compared with boys, the primary school girls had marginally lower SI values. Age-specific average body height and weight were similar in boys and girls (see Table 2).

The CTX analysis group aged 3-8.9 years consisted of 857 boys and 789 girls. Within 1-year age groups, CTX values differed by 
$0.01-0.07 \mathrm{ng} \mathrm{ml}^{-1}$ between both sexes. With increasing age, slightly higher mean CTX values were observed in boys and girls. Boys and girls showed similar age-specific body height and weight values (see Table 3 ).

Age- and sex-specific reference percentiles for SI

Tables 4 and 5 show the 1st, 3rd, 10th, 25th, 50th, 75th, 90th, 97th and 99th SI percentile values by 1-year age groups and height for girls and boys, separately. Figure 4 presents sex-specific reference curves of the 1st, 50th and 99th $\mathrm{SI}$ percentile by age for small, average and tall children (that is, 3rd, 50th and 97th height percentile).

In preschool children, SI percentiles showed a negative association with age and height. In primary school children, a positive association with age and height was observed. The dip in $\mathrm{SI}$ occurred at an older age for higher SI percentiles and was

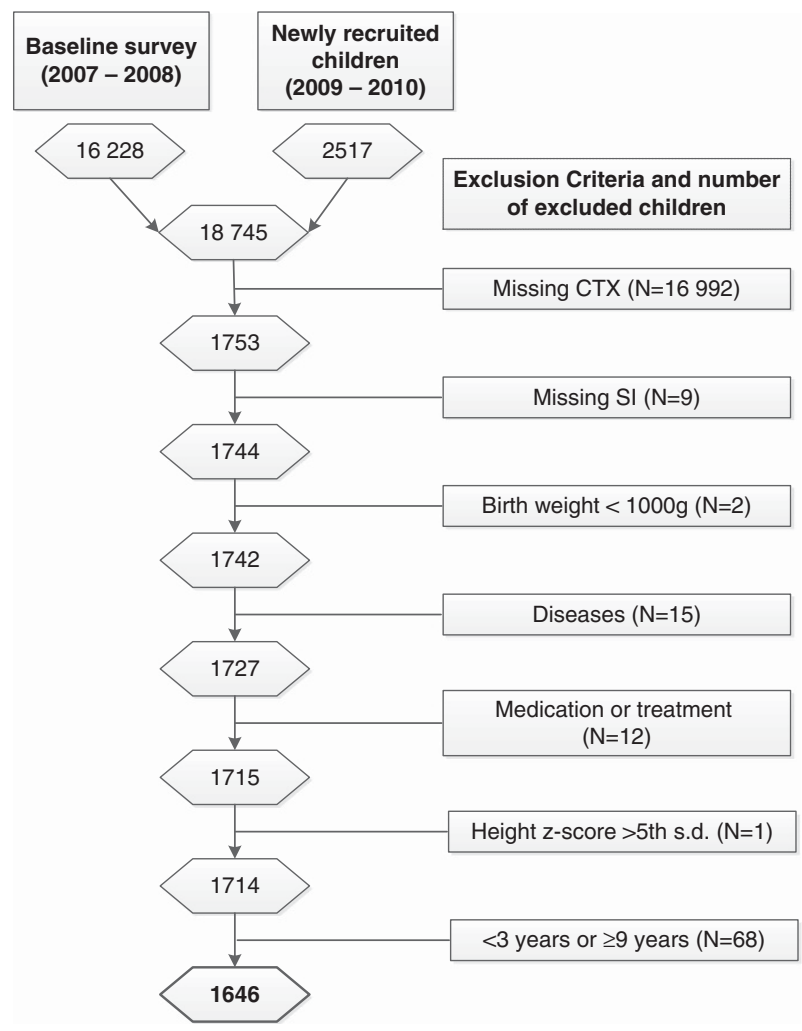

Figure 2. Number of included and excluded children per exclusion criteria for the CTX analysis group from the IDEFICS population.

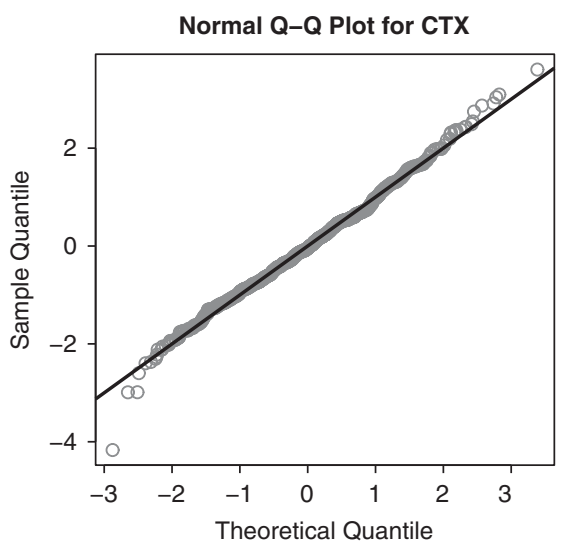

Figure 3. $\mathrm{Q}-\mathrm{Q}$ plot of residuals for $\mathrm{SI}$ and $\mathrm{CTX}$ in boys. observed earlier in taller children than in smaller children. The association of SI with height was inverted around the dip. In boys, height had a smaller effect on SI after the dip compared with girls (Figure 4 and Tables 4 and 5).

Age- and sex-specific reference percentiles for CTX

Tables 6 and 7 show the 1st, 3rd, 10th, 25th, 50th, 75th, 90th, 97th and 99th CTX percentile values by 1-year age groups and height for girls and boys, separately. Figure 5 presents sex-specific reference curves of the 1st, 50th and 99th CTX percentile by age for small, average and tall children. The CTX values showed a linear-positive association with age and height. The impact of height was slightly stronger in boys than in girls.

\section{DISCUSSION}

This study provides the first sex-, age- and height-specific reference values for calcaneal SI and serum CTX for 2-10.9- and 3-8.9-year-old children, respectively. Both analysis groups are based on a population of apparently healthy European children, where standardised QUS and blood measurements were obtained.

The main observation was the negative trend in SI with increasing age and height in preschool children, which was followed by a positive trend in SI with age and height in primary school children. The negative trend of SI in preschool children may be explained by the increased height velocity in early childhood ${ }^{47}$ where bone turnover processes may have not adequately adapted to the growth velocity in young children. Due to the lack of bone reference data in preschool children, no comparison with other data can be made. The few studies in children mostly reported data above the age of 6 years and observed a positive trend of bone parameters with increasing age. ${ }^{21}$ Most bone reference data in children are based on DXA measurements. But it remains questionable to compare QUS with DXA owing to the twodimensional image projection of DXA measures, and the problem that $\mathrm{aBMD}$ is not accounting for growth. Mathematical models were established to calculate the volumetric BMD or bone mineral apparent density, where height, bone area and bone width are considered to avoid under- or overestimation of bone status. ${ }^{16,18,19,22}$ Considering such models, a slight decline in bone mineral apparent density of the femoral neck with increasing age has been observed in primary school children, which is in contrast to our findings. ${ }^{16,19}$

A comparison of our QUS reference data with other QUS reference data should be made with caution. Most of the studies used different methods for calculating reference values or applied different QUS devices (for example, CUBA, Sahara, Sunlight Omnisense) with different measures (for example, speed of sound, broadband ultrasound attenuation) on different body sites (for

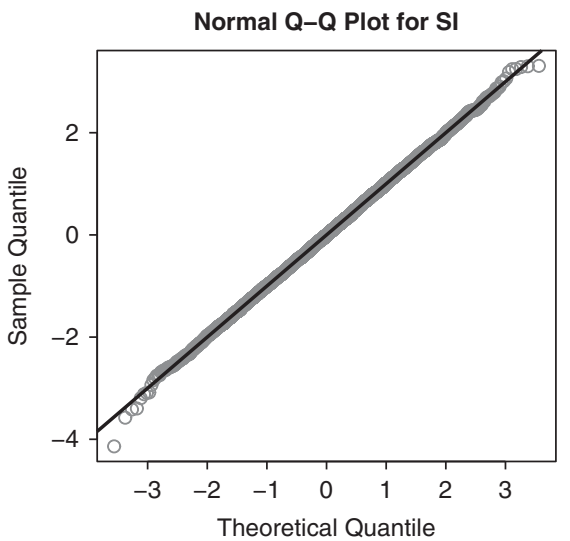


Table 2. Sex-specific SI, height and weight of the IDEFICS SI analysis group, stratified by 1-year age groups

\begin{tabular}{|c|c|c|c|c|c|c|c|c|c|c|}
\hline \multirow{2}{*}{$\begin{array}{l}\text { Age group } \\
\text { (year) }\end{array}$} & \multicolumn{5}{|c|}{ Girls } & \multicolumn{5}{|c|}{ Boys } \\
\hline & $\mathrm{N}$ & $\begin{array}{l}\text { Age (year) } \\
\text { mean } \pm \text { s.d. }\end{array}$ & $\begin{array}{c}S l \\
\text { mean } \pm \text { s.d. }\end{array}$ & $\begin{array}{l}\text { Height }(\mathrm{cm}) \\
\text { mean } \pm \text { s.d. }\end{array}$ & $\begin{array}{l}\text { Weight }(\mathrm{kg}) \\
\text { mean } \pm \text { s.d. }\end{array}$ & $\mathrm{N}$ & $\begin{array}{c}\text { Age (year) } \\
\text { mean } \pm \text { s.d. }\end{array}$ & $\begin{array}{c}S l \\
\text { mean } \pm \text { s.d. }\end{array}$ & $\begin{array}{l}\text { Height }(\mathrm{cm}) \\
\text { mean } \pm \text { s.d. }\end{array}$ & $\begin{array}{l}\text { Weight }(\mathrm{kg}) \\
\text { mean } \pm \text { s.d. }\end{array}$ \\
\hline $2.0-2.9$ & 102 & $2.7 \pm 0.2$ & $84.7 \pm 10.5$ & $93.0 \pm 4.1$ & $13.9 \pm 1.8$ & 116 & $2.6 \pm 0.2$ & $84.6 \pm 11.9$ & $93.9 \pm 4.3$ & $14.6 \pm 1.9$ \\
\hline $3.0-3.9$ & 476 & $3.5 \pm 0.3$ & $82.5 \pm 15.2$ & $100.4 \pm 5.1$ & $16.0 \pm 2.5$ & 495 & $3.5 \pm 0.3$ & $81.7 \pm 13.7$ & $101.0 \pm 4.9$ & $16.2 \pm 2.1$ \\
\hline $4.0-4.9$ & 593 & $4.5 \pm 0.3$ & $82.4 \pm 17.4$ & $106.8 \pm 4.7$ & $18.1 \pm 2.8$ & 670 & $4.5 \pm 0.3$ & $80.2 \pm 15.4$ & $108.1 \pm 5.1$ & $18.6 \pm 3.1$ \\
\hline $5.0-5.9$ & 628 & $5.5 \pm 0.3$ & $80.0 \pm 17.5$ & $113.9 \pm 5.3$ & $20.7 \pm 3.7$ & 680 & $5.5 \pm 0.3$ & $79.1 \pm 16.0$ & $114.7 \pm 5.2$ & $21.0 \pm 3.6$ \\
\hline $6.0-6.9$ & 768 & $6.5 \pm 0.3$ & $76.9 \pm 14.6$ & $120.0 \pm 5.5$ & $23.4 \pm 4.7$ & 762 & $6.5 \pm 0.3$ & $77.8 \pm 13.8$ & $121.3 \pm 5.6$ & $24.1 \pm 4.8$ \\
\hline $7.0-7.9$ & 1104 & $7.5 \pm 0.3$ & $78.8 \pm 11.9$ & $126.7 \pm 5.5$ & $27.0 \pm 5.7$ & 1078 & $7.5 \pm 0.3$ & $80.1 \pm 11.7$ & $127.9 \pm 5.8$ & $27.8 \pm 6.0$ \\
\hline $8.0-8.9$ & 911 & $8.4 \pm 0.3$ & $81.1 \pm 12.0$ & $131.7 \pm 5.9$ & $30.4 \pm 6.6$ & 836 & $8.4 \pm 0.3$ & $82.0 \pm 11.5$ & $132.6 \pm 5.8$ & $30.5 \pm 6.9$ \\
\hline $9.0-9.9$ & 535 & $9.5 \pm 0.3$ & $83.8 \pm 10.6$ & $138.0 \pm 6.7$ & $34.4 \pm 8.5$ & 473 & $9.5 \pm 0.3$ & $84.8 \pm 11.7$ & $139.3 \pm 6.4$ & $36.0 \pm 8.6$ \\
\hline $10.0-10.9$ & 262 & $10.3 \pm 0.3$ & $85.8 \pm 12.6$ & $143.9 \pm 6.5$ & $39.7 \pm 9.9$ & 302 & $10.3 \pm 0.3$ & $87.0 \pm 11.8$ & $142.9 \pm 6.4$ & $39.3 \pm 10.2$ \\
\hline
\end{tabular}

Table 3. Sex-specific CTX, height and weight of the IDEFICS CTX analysis group, stratified by 1-year age groups

\begin{tabular}{|c|c|c|c|c|c|c|c|c|c|c|}
\hline $\begin{array}{l}\text { Age group } \\
\text { (year) }\end{array}$ & $\mathrm{N}$ & $\begin{array}{l}\text { Age (year) } \\
\text { mean } \pm \text { s.d. }\end{array}$ & $\begin{array}{l}C T X\left(n g ~ m l^{-1}\right) \\
\text { mean } \pm \text { s.d. }\end{array}$ & $\begin{array}{l}\text { Height }(\mathrm{cm}) \\
\text { mean } \pm \text { s.d. }\end{array}$ & $\begin{array}{l}\text { Weight }(\mathrm{kg}) \\
\text { mean } \pm \text { s.d. }\end{array}$ & $\mathrm{N}$ & $\begin{array}{l}\text { Age (year) } \\
\text { mean } \pm \text { s.d. }\end{array}$ & $\begin{array}{l}C T X(\mathrm{ng} / \mathrm{ml}) \\
\text { mean } \pm \text { s.d. }\end{array}$ & $\begin{array}{l}\text { Height }(\mathrm{cm}) \\
\text { mean } \pm \text { s.d. }\end{array}$ & $\begin{array}{l}\text { Weight }(\mathrm{kg}) \\
\text { mean } \pm \text { s.d. }\end{array}$ \\
\hline $3.0-3.9$ & 109 & $3.5 \pm 0.3$ & $1.06 \pm 0.24$ & $101.1 \pm 4.8$ & $16.2 \pm 2.9$ & 94 & $3.6 \pm 0.3$ & $1.09 \pm 0.26$ & $102.1 \pm 4.9$ & $16.7 \pm 2.5$ \\
\hline $4.0-4.9$ & 117 & $4.4 \pm 0.3$ & $1.19 \pm 0.28$ & $107.2 \pm 4.2$ & $18.2 \pm 2.6$ & 152 & $4.5 \pm 0.3$ & $1.13 \pm 0.28$ & $108.2 \pm 4.7$ & $18.5 \pm 2.6$ \\
\hline $5.0-5.9$ & 103 & $5.4 \pm 0.3$ & $1.23 \pm 0.30$ & $113.9 \pm 5.2$ & $20.9 \pm 3.8$ & 111 & $5.4 \pm 0.3$ & $1.17 \pm 0.25$ & $114.7 \pm 4.9$ & $20.5 \pm 2.8$ \\
\hline $8.0-8.9$ & 145 & $8.4 \pm 0.3$ & $1.25 \pm 0.29$ & $130.9 \pm 5.6$ & $29.0 \pm 6.2$ & 148 & $8.4 \pm 0.3$ & $1.25 \pm 0.25$ & $131.6 \pm 6.0$ & $28.8 \pm 6.2$ \\
\hline
\end{tabular}

example, radius, phalanx) in different ethnicities. ${ }^{20,48-54}$ The few studies that assessed calcaneal QUS in prepubertal children aged 6-10 years showed a progressive increase of broadband ultrasound attenuation and a small or no increase of speed of sound with age. ${ }^{48,50-52}$ Only two studies established SI reference or normative data in children, adolescents and young adults in the age range from 6 to 21 years. Compared with prepubertal ages, both studies observed a stronger trend in SI with age around the age of 12 years in girls and 14 years in boys. ${ }^{20,54}$ This increase during puberty was also found in studies considering other QUS or DXA bone parameters, indicating that the growth spurt started earlier in girls than boys. ${ }^{14,21,50,51}$ In the present study, no such spurt in SI was observed until the age of 10 years. However, our data showed a positive trend of height in tall 10-year old girls, which may indicate the earlier start of maturation in girls than in boys.

The few published references and normative data on $\mathrm{SI}^{20,54}$ and CTX ${ }^{15,55}$ are not informative regarding age distribution, especially not of the more extreme percentiles, which are of interest for clinical practice. We suggest that the lower the SI percentiles, the more important the meaning of the increase or decrease in SI. In other words, a difference of five SI units between age groups would be more relevant for bone diagnostic at the 3rd SI percentile than at the 50th percentile. For example, an increase of five units in a 5.5-year-old girl with an $\mathrm{SI}$ in the 3rd percentile would result in an improvement of SI from the 3rd to the 10th percentile (see Table 4). The same applies to CTX.

Considering the present $\mathrm{SI}$ reference values, the 3rd age-specific percentile in 5.5-10.9-year-old boys (range: 55.7-69.4) and girls (range: 54.2-69.1) may be considered as a warning threshold for low $\mathrm{SI}$ and reduced skeletal development. The pathological meaning of these values still needs to be evaluated. Only one study investigated $\mathrm{SI}$ values in children with bone disorders: Jaworski et al. ${ }^{27}$ observed a mean SI of $50.6 \pm 13.7$ in eighteen 6- to 13-year old children having osteopenia. According to these findings, our reference values for 5.5-9.5-year- old girls in the 1st age-specific SI percentile (range: 49.9-64.9) are close to this pathological value for osteopenia. The observed range of $15 \mathrm{SI}$ units of the 1 st percentile between the age of 5 and 10 years supports the need for age-specific cut-off values of $\mathrm{SI}$, for example, for predicting osteopenia in childhood.

CTX is mainly used as a bone resorption marker in postmenopausal women. Compared with adults, elevated CTX concentrations of children can be explained by the high skeletal growth velocity and rapid bone turnover. ${ }^{56,57}$ Only one study reported reference values for the 5th, 50th and 95th percentiles established from a smaller sample of 572 Caucasian children. Although a different assay for analysing CTX was used in this study, it showed similar CTX values. ${ }^{15}$ Other studies reported different CTX values in prepubertal children. For example, Crofton et al. $^{55}$ observed a $95 \%$ reference interval (median of 0.352 $\mathrm{ng} \mathrm{ml}^{-1}$ ) be1tween 0.146 and $0.818 \mathrm{ng} \mathrm{ml}^{-1}$ in a small study sample of 124 Caucasian boys and girls aged 1-9 years. These concentrations are below the reference range of our 3-8-year-old CTX study sample, which varied between 0.20 and $2.03 \mathrm{ng} \mathrm{ml}^{-1}$. In contrast, Ambroszkiewiki et al. ${ }^{58}$ reported different means of CTX in 100 vegetarian $\left(1.697 \pm 0.653 \mathrm{ng} \mathrm{ml}^{-1}\right)$ and omnivorous children $\left(1.99 \pm 0.30 \mathrm{ng} \mathrm{ml}^{-1}\right)$ aged 2-10 years, which compares with a lower mean of CTX in our study group $\left(1.19 \pm 0.27 \mathrm{ng} \mathrm{ml}^{-1}\right)$. Crofton et al. and Ambroszkiewiki et al. used a different assay for analysing CTX which may be one reason for the differences.

To present reference values that are not affected by disturbed skeletal development due to very low birth weight, diseases or 


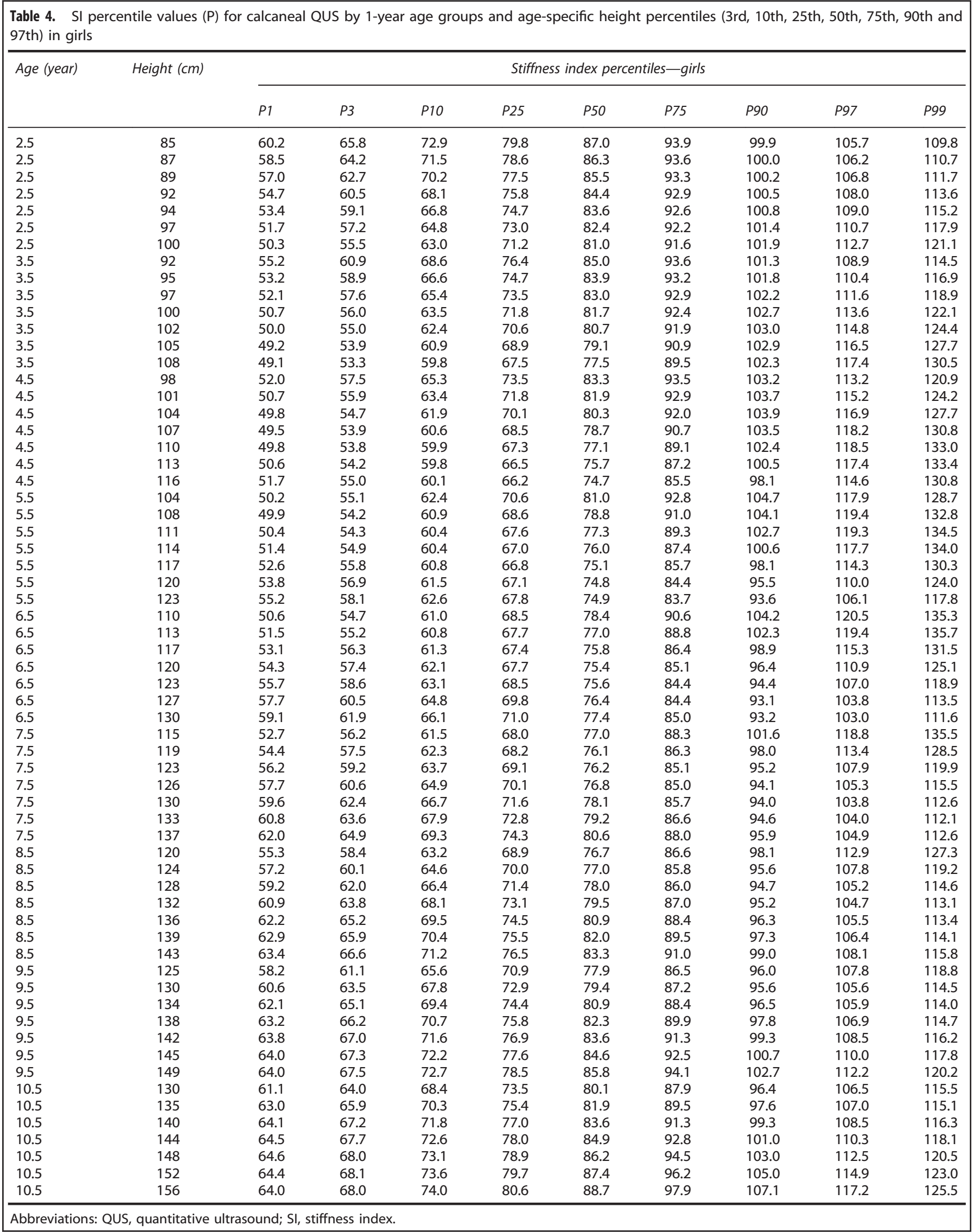


Table 5. SI percentile values (P) for calcaneal quantitative ultrasound by 1-year age groups and age-specific height percentiles (3rd, 10th, 25th, 50th, 75th, 90th and 97th) in boys

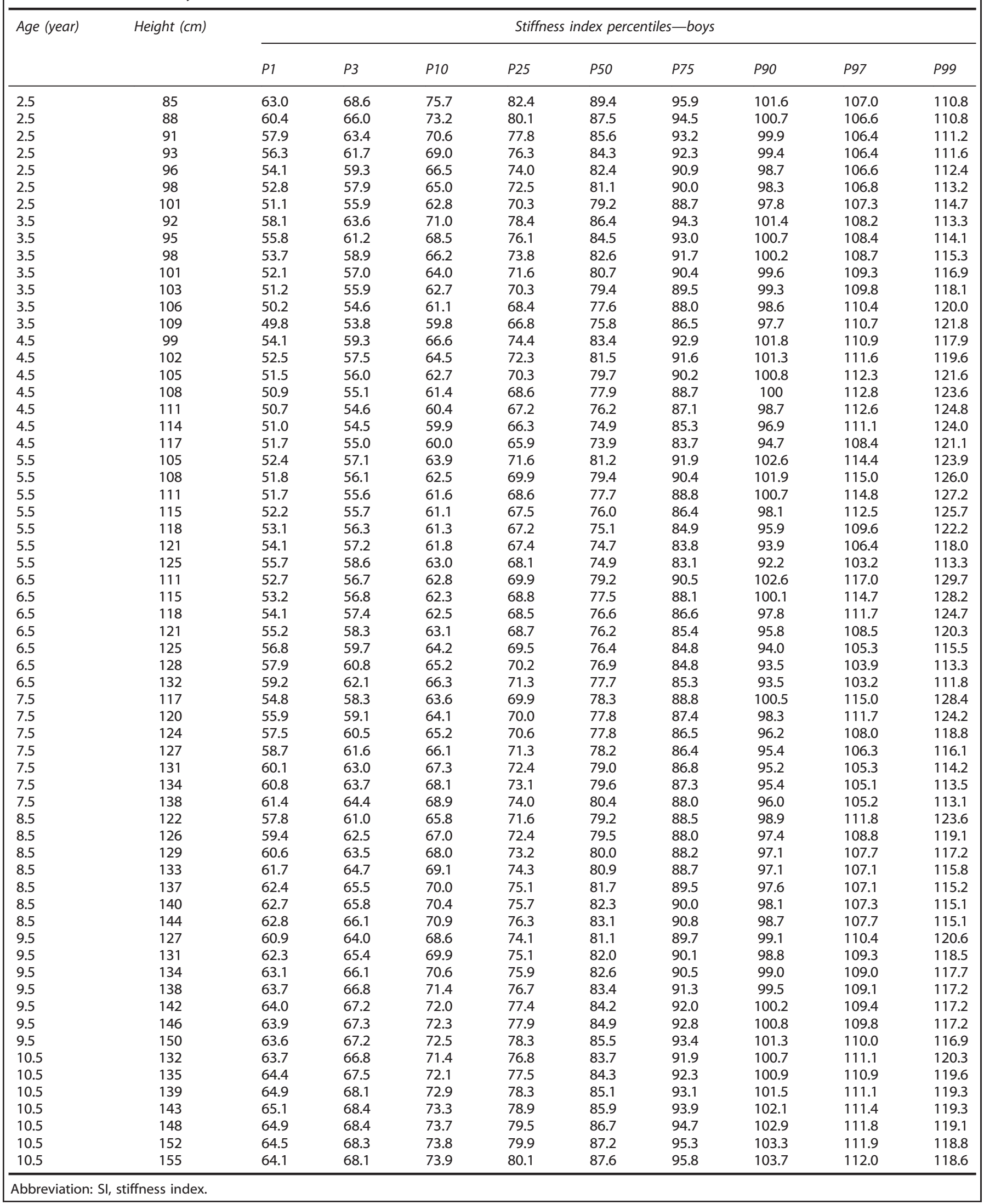



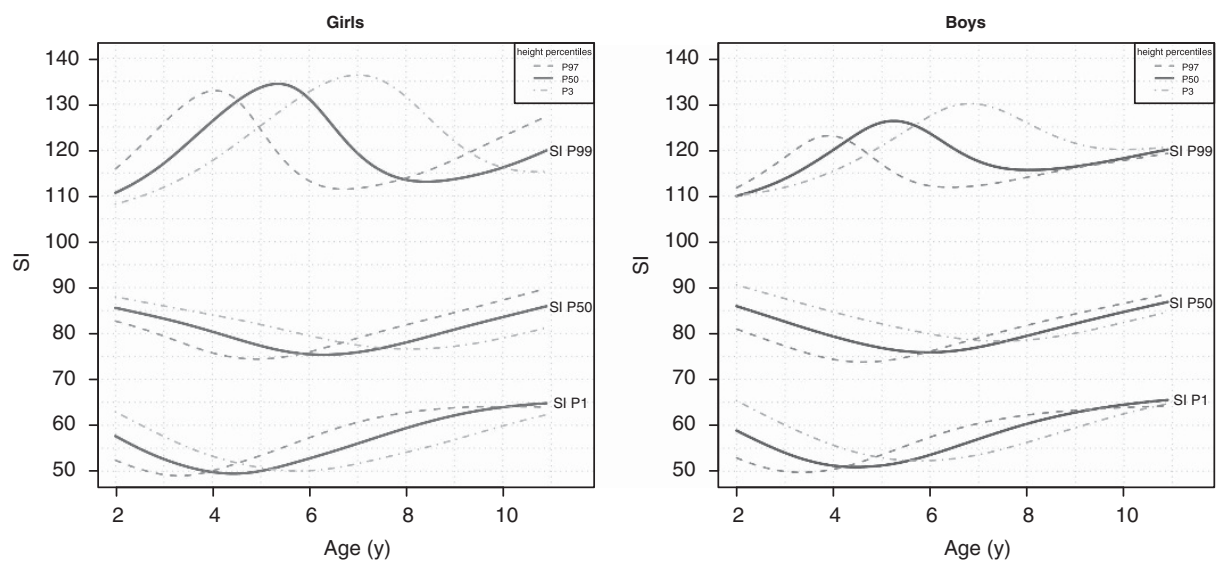

Figure 4. SI reference curves of the 1st, 50th and 99th percentiles (P) for girls and boys considering the 3rd, 50th and 97th age- and sex-specific height percentiles.

\begin{tabular}{|c|c|c|c|c|c|c|c|c|c|c|}
\hline \multirow{2}{*}{$\begin{array}{l}\text { Age } \\
\text { (year) }\end{array}$} & \multirow{2}{*}{$\begin{array}{c}\text { Height } \\
(\mathrm{cm})\end{array}$} & \multicolumn{9}{|c|}{ CTX percentiles—girls } \\
\hline & & P1 & P3 & P10 & $P 25$ & P50 & P75 & $P 90$ & $P 97$ & P99 \\
\hline 3.5 & 92 & 0.42 & 0.54 & 0.70 & 0.86 & 1.05 & 1.23 & 1.39 & 1.55 & 1.67 \\
\hline 3.5 & 95 & 0.44 & 0.56 & 0.72 & 0.89 & 1.07 & 1.25 & 1.41 & 1.58 & 1.70 \\
\hline 3.5 & 97 & 0.46 & 0.58 & 0.74 & 0.90 & 1.09 & 1.27 & 1.43 & 1.59 & 1.71 \\
\hline 3.5 & 100 & 0.48 & 0.60 & 0.76 & 0.93 & 1.11 & 1.29 & 1.46 & 1.62 & 1.74 \\
\hline 3.5 & 102 & 0.50 & 0.62 & 0.78 & 0.94 & 1.13 & 1.31 & 1.47 & 1.63 & 1.75 \\
\hline 3.5 & 105 & 0.52 & 0.64 & 0.81 & 0.97 & 1.15 & 1.33 & 1.50 & 1.66 & 1.78 \\
\hline 3.5 & 108 & 0.55 & 0.67 & 0.83 & 0.99 & 1.17 & 1.36 & 1.52 & 1.68 & 1.80 \\
\hline 4.5 & 98 & 0.45 & 0.57 & 0.73 & 0.90 & 1.08 & 1.26 & 1.42 & 1.59 & 1.71 \\
\hline 4.5 & 101 & 0.48 & 0.60 & 0.76 & 0.92 & 1.10 & 1.28 & 1.45 & 1.61 & 1.73 \\
\hline 4.5 & 104 & 0.50 & 0.62 & 0.78 & 0.95 & 1.13 & 1.31 & 1.47 & 1.63 & 1.75 \\
\hline 4.5 & 107 & 0.52 & 0.64 & 0.81 & 0.97 & 1.15 & 1.33 & 1.50 & 1.66 & 1.78 \\
\hline 4.5 & 110 & 0.55 & 0.67 & 0.83 & 0.99 & 1.18 & 1.36 & 1.52 & 1.68 & 1.80 \\
\hline 4.5 & 113 & 0.57 & 0.69 & 0.85 & 1.02 & 1.20 & 1.38 & 1.55 & 1.71 & 1.83 \\
\hline 4.5 & 116 & 0.60 & 0.72 & 0.88 & 1.04 & 1.22 & 1.41 & 1.57 & 1.73 & 1.85 \\
\hline 5.5 & 104 & 0.49 & 0.61 & 0.77 & 0.93 & 1.11 & 1.29 & 1.46 & 1.62 & 1.74 \\
\hline 5.5 & 108 & 0.52 & 0.64 & 0.80 & 0.96 & 1.14 & 1.33 & 1.49 & 1.65 & 1.77 \\
\hline 5.5 & 111 & 0.54 & 0.66 & 0.82 & 0.99 & 1.17 & 1.35 & 1.51 & 1.68 & 1.80 \\
\hline 5.5 & 114 & 0.57 & 0.69 & 0.85 & 1.01 & 1.19 & 1.37 & 1.54 & 1.70 & 1.82 \\
\hline 5.5 & 117 & 0.59 & 0.71 & 0.87 & 1.04 & 1.22 & 1.40 & 1.56 & 1.72 & 1.84 \\
\hline 5.5 & 120 & 0.61 & 0.73 & 0.90 & 1.06 & 1.24 & 1.42 & 1.59 & 1.75 & 1.87 \\
\hline 5.5 & 123 & 0.64 & 0.76 & 0.92 & 1.08 & 1.27 & 1.45 & 1.61 & 1.77 & 1.89 \\
\hline 6.5 & 110 & 0.52 & 0.64 & 0.80 & 0.96 & 1.15 & 1.33 & 1.49 & 1.65 & 1.77 \\
\hline 6.5 & 113 & 0.54 & 0.66 & 0.82 & 0.99 & 1.17 & 1.35 & 1.51 & 1.68 & 1.80 \\
\hline 6.5 & 117 & 0.58 & 0.70 & 0.86 & 1.02 & 1.20 & 1.38 & 1.55 & 1.71 & 1.83 \\
\hline 6.5 & 120 & 0.60 & 0.72 & 0.88 & 1.04 & 1.23 & 1.41 & 1.57 & 1.73 & 1.85 \\
\hline 6.5 & 123 & 0.62 & 0.74 & 0.91 & 1.07 & 1.25 & 1.43 & 1.60 & 1.76 & 1.88 \\
\hline 6.5 & 127 & 0.66 & 0.78 & 0.94 & 1.10 & 1.28 & 1.46 & 1.63 & 1.79 & 1.91 \\
\hline 6.5 & 130 & 0.68 & 0.80 & 0.96 & 1.13 & 1.31 & 1.49 & 1.65 & 1.81 & 1.93 \\
\hline 7.5 & 115 & 0.54 & 0.66 & 0.83 & 0.99 & 1.17 & 1.35 & 1.52 & 1.68 & 1.80 \\
\hline 7.5 & 119 & 0.58 & 0.70 & 0.86 & 1.02 & 1.20 & 1.38 & 1.55 & 1.71 & 1.83 \\
\hline 7.5 & 123 & 0.61 & 0.73 & 0.89 & 1.05 & 1.24 & 1.42 & 1.58 & 1.74 & 1.86 \\
\hline 7.5 & 126 & 0.63 & 0.75 & 0.91 & 1.08 & 1.26 & 1.44 & 1.60 & 1.77 & 1.89 \\
\hline 7.5 & 130 & 0.67 & 0.79 & 0.95 & 1.11 & 1.29 & 1.47 & 1.64 & 1.80 & 1.92 \\
\hline 7.5 & 133 & 0.69 & 0.81 & 0.97 & 1.13 & 1.32 & 1.50 & 1.66 & 1.82 & 1.94 \\
\hline 7.5 & 137 & 0.72 & 0.84 & 1.00 & 1.17 & 1.35 & 1.53 & 1.69 & 1.85 & 1.98 \\
\hline 8.5 & 120 & 0.57 & 0.69 & 0.85 & 1.01 & 1.20 & 1.38 & 1.54 & 1.70 & 1.82 \\
\hline 8.5 & 124 & 0.60 & 0.72 & 0.88 & 1.05 & 1.23 & 1.41 & 1.57 & 1.73 & 1.85 \\
\hline 8.5 & 128 & 0.63 & 0.75 & 0.92 & 1.08 & 1.26 & 1.44 & 1.61 & 1.77 & 1.89 \\
\hline 8.5 & 132 & 0.67 & 0.79 & 0.95 & 1.11 & 1.29 & 1.47 & 1.64 & 1.80 & 1.92 \\
\hline 8.5 & 136 & 0.70 & 0.82 & 0.98 & 1.14 & 1.33 & 1.51 & 1.67 & 1.83 & 1.95 \\
\hline 8.5 & 139 & 0.72 & 0.84 & 1.00 & 1.17 & 1.35 & 1.53 & 1.69 & 1.86 & 1.98 \\
\hline 8.5 & 143 & 0.75 & 0.87 & 1.04 & 1.20 & 1.38 & 1.56 & 1.73 & 1.89 & 2.01 \\
\hline
\end{tabular}

Table 7. Percentile values (P) of CTX by 1-year age groups and agespecific height percentiles (3rd, 10th, 25th, 50th, 75th, 90th and 97th) in boys

\begin{tabular}{|c|c|c|c|c|c|c|c|c|c|c|}
\hline \multirow{2}{*}{$\begin{array}{l}\text { Age } \\
\text { (year) }\end{array}$} & \multirow{2}{*}{$\begin{array}{c}\text { Height } \\
(\mathrm{cm})\end{array}$} & \multicolumn{9}{|c|}{ CTX percentiles-boys } \\
\hline & & P1 & P3 & P10 & $P 25$ & P50 & P75 & P90 & P97 & P99 \\
\hline 3.5 & 92 & 0.39 & 0.51 & 0.66 & 0.81 & 0.98 & 1.15 & 1.31 & 1.46 & 1.57 \\
\hline 3.5 & 95 & 0.42 & 0.54 & 0.69 & 0.84 & 1.02 & 1.19 & 1.34 & 1.49 & 1.61 \\
\hline 3.5 & 98 & 0.46 & 0.57 & 0.72 & 0.88 & 1.05 & 1.22 & 1.37 & 1.52 & 1.64 \\
\hline 3.5 & 101 & 0.49 & 0.60 & 0.75 & 0.91 & 1.08 & 1.25 & 1.40 & 1.56 & 1.67 \\
\hline 3.5 & 103 & 0.51 & 0.62 & 0.77 & 0.93 & 1.10 & 1.27 & 1.43 & 1.58 & 1.69 \\
\hline 3.5 & 106 & 0.54 & 0.65 & 0.81 & 0.96 & 1.13 & 1.30 & 1.46 & 1.61 & 1.72 \\
\hline 3.5 & 109 & 0.57 & 0.69 & 0.84 & 0.99 & 1.16 & 1.34 & 1.49 & 1.64 & 1.75 \\
\hline 4.5 & 99 & 0.44 & 0.55 & 0.70 & 0.85 & 1.03 & 1.20 & 1.35 & 1.50 & 1.62 \\
\hline 4.5 & 102 & .47 & 0.58 & 0.73 & 0.89 & 1.06 & 1.23 & 1.38 & 1.54 & 1.65 \\
\hline 4.5 & 105 & .50 & 0.61 & 0.76 & 0.92 & 1.09 & 1.26 & 1.42 & 1.57 & 1.68 \\
\hline 4.5 & 108 & .53 & 0.64 & 0.80 & 0.95 & 1.12 & 1.29 & 1.45 & 1.60 & 1.71 \\
\hline 4.5 & 111 & 0.56 & 0.68 & 0.83 & 0.98 & 1.15 & 1.32 & 1.48 & 1.63 & 1.74 \\
\hline 4.5 & 114 & 0.59 & 0.71 & 0.86 & 1.01 & 1.19 & 1.36 & 1.51 & 1.66 & 1.78 \\
\hline 4.5 & 117 & 0.63 & 0.74 & 0.89 & 1.05 & 1.22 & 1.39 & 1.54 & 1.70 & 1.81 \\
\hline 5.5 & 105 & 0.47 & 0.58 & 0.73 & 0.89 & 1.06 & 1.23 & 1.38 & 1.54 & 1.65 \\
\hline 5.5 & & & 0.61 & 0.76 & 0.92 & 1.09 & 1.26 & 1.42 & 1.57 & 1.68 \\
\hline 5.5 & 111 & 0.53 & 0.64 & 0.80 & 0.95 & 1.12 & 1.29 & 1.45 & 1.60 & 1.71 \\
\hline 5.5 & & & 0.69 & 0.84 & 0.99 & 1.16 & 1.34 & 1.49 & 1.64 & 1.76 \\
\hline 5.5 & 18 & .61 & 0.72 & 0.87 & 1.03 & 1.20 & 1.37 & 1.52 & 1.67 & 1.7 \\
\hline 5.5 & 121 & 0.64 & 0.75 & 0.90 & 1.06 & 1.23 & 1.40 & 1.55 & 1.71 & 1.82 \\
\hline 5.5 & 125 & .68 & 0.79 & 0.95 & 1.10 & 1.27 & 1.44 & 1.60 & 1.75 & 1.8 \\
\hline 6.5 & 111 & .50 & 0.61 & 0.76 & 0.92 & 1.09 & 1.26 & 1.42 & 1.57 & 1.68 \\
\hline 6.5 & & & 0.66 & 0.81 & 0.96 & 1.7 & 1.30 & 1.46 & 1.61 & 1.72 \\
\hline 6.5 & 118 & 0.57 & 0.69 & 0.84 & 0.99 & 1.16 & 1.34 & 1.49 & 1.64 & 1.7 \\
\hline 6.5 & 121 & 0.61 & 0.72 & 0.87 & 1.03 & 1.20 & 1.37 & 1.52 & 1.67 & 1.7 \\
\hline 6.5 & 125 & 65 & 0.76 & 0.91 & 1.07 & 1.24 & 1.41 & 1.56 & 1.72 & 1.8 \\
\hline 6.5 & 128 & .68 & 0.79 & 0.95 & 1.10 & 1.27 & 1.44 & 1.60 & 1.75 & 1.86 \\
\hline 6.5 & & & 0.84 & 0.99 & 1.14 & 1.31 & 1.48 & 1.64 & 1.79 & 1.90 \\
\hline 7.5 & 117 & .53 & 0.64 & 0.80 & 0.95 & 1.12 & 1.29 & 1.45 & 1.60 & 1.7 \\
\hline 7.5 & 120 & 0.56 & 0.68 & 0.83 & 0.98 & 1.15 & 1.33 & 1.48 & 1.63 & 1.7 \\
\hline 7.5 & 124 & 0.61 & 0.72 & 0.87 & 1.03 & 1.20 & 1.37 & 1.52 & 1.67 & 1.79 \\
\hline 7.5 & 127 & 0.64 & 0.75 & 0.90 & 1.06 & 1.23 & 1.40 & 1.55 & 1.71 & 1.82 \\
\hline 7.5 & & & 0.79 & 0.95 & 1.10 & 1.27 & 1.44 & 1.60 & 1.75 & 1.8 \\
\hline 7.5 & 13 & & 0.83 & 0.98 & 1.13 & 1.30 & 1.47 & 1.63 & 1.78 & 1.8 \\
\hline 7.5 & 13 & 0.75 & 0.87 & 1.02 & 1.17 & 1.35 & 1.52 & 1.67 & 1.82 & 1.9 \\
\hline 8.5 & 122 & 0.55 & 0.67 & 0.82 & 0.97 & 1.14 & 1.32 & 1.47 & 1.62 & 1.7 \\
\hline 8.5 & 126 & 0.60 & 0.71 & 0.86 & 1.02 & 1.19 & 1.36 & 1.51 & 1.66 & $1.7 \varepsilon$ \\
\hline 8.5 & 129 & & 0.74 & 0.89 & 1.05 & 1.22 & 1.39 & 1.54 & 1.70 & 1.8 \\
\hline 8.5 & 133 & 0.67 & 0.78 & 0.94 & 1.09 & 1.26 & 1.43 & 1.59 & 1.74 & 1.8 \\
\hline 8.5 & & & 0.83 & 0.98 & 1.13 & 1.30 & 1.47 & 1.63 & 1.78 & 1.8 \\
\hline 8.5 & 140 & 0.74 & 0.86 & 1.01 & 1.16 & 1.34 & 1.51 & 1.66 & 1.81 & 1.9 \\
\hline 8.5 & 144 & 0.79 & 0.90 & 1.05 & 1.21 & 1.38 & 1.55 & 1.70 & 1.86 & 1.9 \\
\hline
\end{tabular}

Abbreviation: CTX, cross-linking telopeptide of type I collagen. 

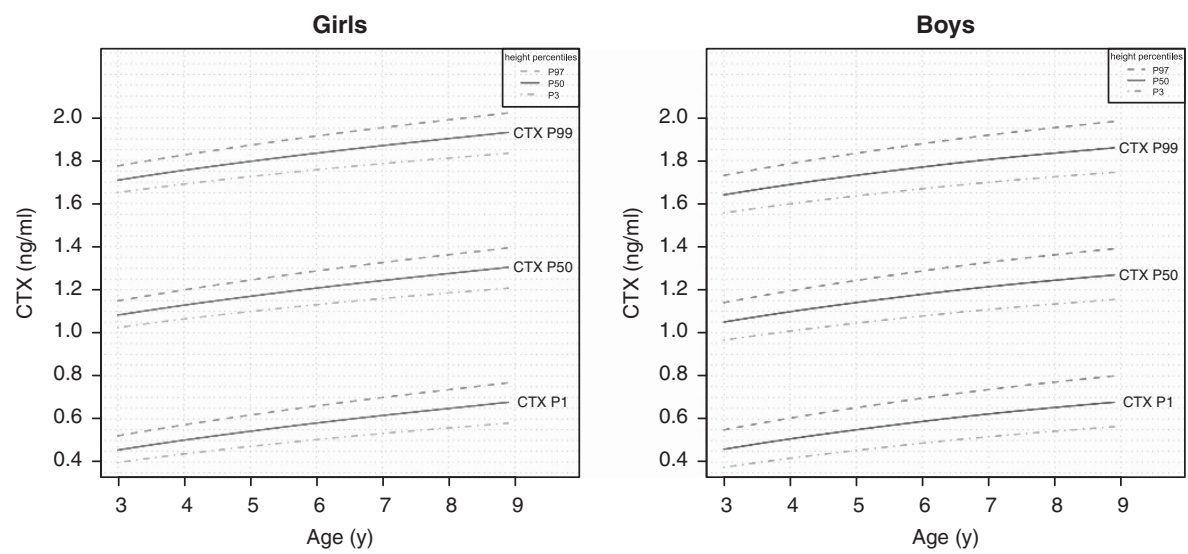

Figure 5. CTX reference curves of the 1st, 50th and 99th percentiles (P) for girls and boys considering the 3rd, 50th and 97th age- and sex-specific height percentile.

medical treatments that directly affect bone metabolism, children with these conditions were excluded. Fat mass may also have a pathophysiological effect on bone metabolism. ${ }^{2-4}$ This is further supported by Eliakim et al. ${ }^{59}$ who showed reduced QUS measures in obese compared to non-obese children. Furthermore, a pathophysiological relationship of excessive thinness on bone health has been reported. ${ }^{60}$ We performed sensitivity analyses to test the robustness of the SI and CTX reference percentiles comparing one model excluding underweight (stage 3 according the International Obesity Task Force criteria) ${ }^{42}$ and obese children with our main model in which these children were included. SI and CTX values obtained from both models had only minor deviations (Supplementary Figures A and B). Therefore, we retained underweight and obese children in the analysis group. Reference curves excluding underweight and obese children are provided in (Supplementary Figures $C$ and D).

A limitation of this study is the cross-sectional design. Longitudinal data of individuals give more accurate reference data. Furthermore, the lack of studies investigating long-term sequels of low SI or inadequate CTX concentrations limits our ability to propose risk-based cut-offs. We investigated serum CTX as an indicator of bone metabolism. Several studies highlighted the importance of considering more than one bone metabolic marker, that is, at least one bone formation and resorption marker each, for assessing reduced bone turnover or a decreased skeletal development. $^{15}$

The use of an unselected, large and heterogeneous sample of apparently healthy European children with different living conditions and providing data on SI and CTX using standardised QUS, blood and anthropometric measures is a strength of the current study. Furthermore, the large examination programme of the IDEFICS study allowed the exclusion of children suffering from conditions, diseases or that received medical treatments possibly affecting bone metabolism. As an additional strength, this study is the first applying an improved statistical method to derive SI and CTX reference percentiles by modelling age and height simultaneously.

\section{CONCLUSION}

This is the first paper providing sex-, age- and height-specific reference values of SI and serum CTX for European children aged 2-10.9 years and 3-8.9 years, respectively, based on a large and apparently healthy cohort. These reference values lay the ground to evaluate bone growth and metabolism in children in epidemiological and clinical studies. They are also of immediate use for clinical practice in children receiving treatments that possibly affect bone health as well as to monitor their skeletal development. However, to apply the present reference values, the use of different QUS brands (e.g. CUBA, Sahara, Sunlight) or CTX assays should be considered. These reference values will be complemented by data of adolescents participating in the followup survey of the IDEFICS study (I.Family).

\section{CONFLICT OF INTEREST}

The authors declare no conflict of interest.

\section{ACKNOWLEDGEMENTS}

This work was done as part of the IDEFICS study (www.idefics.eu). We gratefully acknowledge the financial support of the European community within the Sixth RTD Framework Programme Contract No. 016181 (FOOD). Isabelle Sioen is financially supported by the Research Foundation Flanders (Grant no. 1.2.683.14.N.00). In addition, the authors are grateful to the Volkswagen Foundation that financially supported the production of this supplement. The information in this document reflects the author's view and is provided as is.

\section{REFERENCES}

1 Herrmann D, Hebestreit A, Ahrens W. Impact of physical activity and exercise on bone health in the life course: a review. Bundesgesundheitsblatt Gesundheitsforschung Gesundheitsschutz 2012; 55: 35-54.

2 Viljakainen HT, Pekkinen M, Saarnio E, Karp H, Lamberg-Allardt C, Makitie O. Dual effect of adipose tissue on bone health during growth. Bone 2011; 48: 212-217.

3 Dimitri P, Wales JK, Bishop N. Adipokines, bone-derived factors and bone turnover in obese children; evidence for altered fat-bone signalling resulting in reduced bone mass. Bone 2011; 48: 189-196.

4 Cao JJ. Effects of obesity on bone metabolism. J Orthop Surg Res 2011; 6: 30.

5 da Fonseca MA. Osteoporosis: an increasing concern in pediatric dentistry. Pediatr Dent 2011; 33: 241-245.

6 Makitie O. Causes, mechanisms and management of paediatric osteoporosis. Nat Rev Rheumatol 2013; 9: 465-475.

7 Rizzoli R, Bianchi ML, Garabedian M, McKay HA, Moreno LA. Maximizing bone mineral mass gain during growth for the prevention of fractures in the adolescents and the elderly. Bone 2010; 46: 294-305.

8 Foley S, Quinn S, Jones G. Tracking of bone mass from childhood to adolescence and factors that predict deviation from tracking. Bone 2009; 44: 752-757.

9 Fujita Y, Iki M, lkeda Y, Morita A, Matsukura T, Nishino $\mathrm{H}$ et al. Tracking of appendicular bone mineral density for 6 years including the pubertal growth spurt: Japanese Population-based Osteoporosis kids cohort study. J Bone Miner Metab 2011; 29: 208-216.

10 Yi KH, Hwang JS, Kim EY, Lee JA, Kim DH, Lim JS. Reference values for bone mineral density according to age with body size adjustment in Korean children and adolescents. J Bone Miner Metab 2013 2014, 32: 281-289.

11 Boyce AM, Gafni RI. Approach to the child with fractures. J Clin Endocrinol Metab 2011; 96: 1943-1952. 
12 Gafni Rl, McCarthy EF, Hatcher T, Meyers JL, Inoue N, Reddy C et al. Recovery from osteoporosis through skeletal growth: early bone mass acquisition has little effect on adult bone density. FASEB J 2002; 16: 736-738.

13 Mora S, Barera G, Ricotti A, Weber G, Bianchi C, Chiumello G. Reversal of low bone density with a gluten-free diet in children and adolescents with celiac disease. $A m$ J Clin Nutr 1998; 67: 477-481.

14 Zemel BS, Kalkwarf HJ, Gilsanz V, Lappe JM, Oberfield S, Shepherd JA et al. Revised reference curves for bone mineral content and areal bone mineral density according to age and sex for black and non-black children: results of the bone mineral density in childhood study. J Clin Endocrinol Metab 2011; 96: 3160-3169.

15 Rauchenzauner M, Schmid A, Heinz-Erian P, Kapelari K, Falkensammer G, Griesmacher $A$ et al. Sex- and age-specific reference curves for serum markers of bone turnover in healthy children from 2 months to 18 years. J Clin Endocrinol Metab 2007; 92: 443-449.

16 Ward KA, Ashby RL, Roberts SA, Adams JE, Zulf MM. UK reference data for the Hologic QDR Discovery dual-energy $x$ ray absorptiometry scanner in healthy children and young adults aged 6-17 years. Arch Dis Child 2007; 92: 53-59.

17 Gallo S, Vanstone CA, Weiler HA. Normative data for bone mass in healthy term infants from birth to 1 year of age. J Osteoporos 2012; 2012: 672403.

18 Guo B, Xu Y, Gong J, Tang Y, Xu H. Age trends of bone mineral density and percentile curves in healthy Chinese children and adolescents. J Bone Miner Metab 2013; 31: 304-314.

19 Khadilkar AV, Sanwalka NJ, Chiplonkar SA, Khadilkar VV, Mughal MZ. Normative data and percentile curves for Dual Energy X-ray Absorptiometry in healthy Indian girls and boys aged 5-17 years. Bone 2011; 48: 810-819.

20 Alwis G, Rosengren B, Nilsson JA, Stenevi-Lundgren S, Sundberg M, Sernbo I et al. Normative calcaneal quantitative ultrasound data as an estimation of skeletal development in Swedish children and adolescents. Calcif Tissue Int 2010; 87: 493-506.

21 Kalkwarf HJ, Zemel BS, Gilsanz V, Lappe JM, Horlick M, Oberfield S et al. The bone mineral density in childhood study: bone mineral content and density according to age, sex, and race. J Clin Endocrinol Metab 2007; 92: 2087-2099.

22 Baroncelli Gl, Bertelloni S, Ceccarelli C, Saggese G. Measurement of volumetric bone mineral density accurately determines degree of lumbar undermineralization in children with growth hormone deficiency. J Clin Endocrinol Metab 1998; 83: 3150-3154.

23 Weber LT, Mehls O. Limitations of dual x-ray absorptiometry in children with chronic kidney disease. Pediatr Nephrol 2010; 25: 3-5.

24 Baroncelli Gl. Quantitative ultrasound methods to assess bone mineral status in children: technical characteristics, performance, and clinical application. Pediatr Res 2008; 63: 220-228.

25 Trimpou P, Bosaeus I, Bengtsson BA, Landin-Wilhelmsen K. High correlation between quantitative ultrasound and DXA during 7 years of follow-up. Eur $J$ Radiol 2010; 73: 360-364.

26 Ahuja SP, Greenspan SL, Lin Y, Bowen A, Bartels D, Goyal RK. A pilot study of heel ultrasound to screen for low bone mass in children with leukemia. J Pediatr Hematol Oncol 2006; 28: 427-432.

27 Jaworski M, Lebiedowski M, Lorenc RS, Trempe J. Ultrasound bone measurement in pediatric subjects. Calcif Tissue Int 1995; 56: 368-371.

28 Khaw KT, Reeve J, Luben R, Bingham S, Welch A, Wareham N et al. Prediction of total and hip fracture risk in men and women by quantitative ultrasound of the calcaneus: EPIC-Norfolk prospective population study. Lancet 2004; 363: 197-202.

29 The International Society for Clinical Densitometry (ISCD). Pediatric Official Positions of the International Society for Clinical Densitometry 2007. http://www.iscd. org/official-positions/official-positions/ (last accessed April 2014).

30 Szulc $P$, Seeman E, Delmas PD. Biochemical measurements of bone turnover in children and adolescents. Osteoporos Int 2000; 11: 281-294.

31 Bayer M. Reference values of osteocalcin and procollagen type I N-propeptide plasma levels in a healthy Central European population aged 0-18 years. Osteoporos Int 2014; 25: 729-736.

32 Rigby RA, Stasinopoulos DM. Generalized additive models for location, scale and shape. J R Stat Soc 2005; 54: 507-554.

33 Cole TJ, Stanojevic S, Stocks J, Coates AL, Hankinson JL, Wade AM. Age- and size-related reference ranges: a case study of spirometry through childhood and adulthood. Stat Med 2009; 28: 880-898.

34 Ahrens W, Bammann K, Siani A, Buchecker K, De Henauw S, lacoviello L et al. IDEFICS consortium. The IDEFICS cohort: design, characteristics and participation in the baseline survey. Int J Obes (Lond) 2011; 35: S3-S15.

35 Ahrens W, Bammann K, de Henauw S, Halford J, Palou A, Pigeot I et al. European Consortium of the IDEFICS Project Understanding and preventing childhood obesity and related disorders-IDEFICS: a European multilevel epidemiological approach. Nutr Metab Cardiovasc Dis 2006; 16: 302-308.
36 Bammann K, Peplies J, Pigeot I, Ahrens W. IDEFICS: a multicenter European project on diet- and lifestyle-related disorders in children. Med Klin (Munich) 2007; 102: 230-235.

37 ICD-10 Version 2010. http://apps.who.int/classifications/icd10/browse/2010/en (last accessed April 2014).

38 van de Lagemaat M, Rotteveel J, van Weissenbruch MM, Lafeber HN. Small-forgestational-age preterm-born infants already have lower bone mass during early infancy. Bone 2012; 51: 441-446.

39 ATC/DDD Index. http://www.whocc.no/atc_ddd_index/ (last access April 2014).

40 Cole TJ, Freeman JV, Preece MA. British 1990 growth reference centiles for weight, height, body mass index and head circumference fitted by maximum penalized likelihood. Stat Med 1998; 17: 407-429.

41 GE Healthcare. Lunar Achilles InSightTM. Operator's Manual. Medical Systems Lunar: Madison, WI, USA, 2006.

42 Cole TJ, Lobstein T. Extended international (IOTF) body mass index cut-offs for thinness, overweight and obesity. Pediatr Obes 2012; 7: 284-294.

43 Tyrrell VJ, Richards G, Hofman P, Gillies GF, Robinson E, Cutfield WS. Foot-to-foot bioelectrical impedance analysis: a valuable tool for the measurement of body composition in children. Int J Obes Relat Metab Disord 2001; 25: 273-278.

44 Wells JC, Cole TJ. Adjustment of fat-free mass and fat mass for height in children aged 8 y. Int J Obes Relat Metab Disord 2002; 26: 947-952.

45 Stasinopoulos DM, Rigby RA. Generalized additive models for location, scale and shape (GAMLSS). J Stat Softw 2007; 23: 1-46.

46 van BS, Fredriks $M$. Worm plot: a simple diagnostic device for modelling growth reference curves. Stat Med 2001; 20: 1259-1277.

47 Hermanussen, M. Auxology. Studying Human Growth. Schweizerbart Science Publishers: Stuttgart, Germany, 2013.

48 Goh SY, Aragon JM, Lee YS, Loke KY.. Normative data for quantitative calcaneal ultrasound in Asian children. Ann Acad Med Singapore 2011; 40: 74-79.

49 Pedrotti L, Bertani B, Tuvo G, Barone F, Crivellari I, Lucanto S et al. Evaluation of bone density in infancy and adolescence. Review of medical literature and personal experience. Clin Cases Miner Bone Metab 2010; 7: 102-108.

50 van den Bergh JP, Noordam C, Ozyilmaz A, Hermus AR, Smals AG, Otten BJ. Calcaneal ultrasound imaging in healthy children and adolescents: relation of the ultrasound parameters BUA and SOS to age, body weight, height, foot dimensions and pubertal stage. Osteoporos Int 2000; 11: 967-976.

51 Wünsche K, Wünsche B, Fähnrich H, Mentzel HJ, Vogt S, Abendroth K et al. Ultrasound bone densitometry of the os calcis in children and adolescents. Calcif Tissue Int 2000; 67: 349-355.

52 Mughal MZ, Ward K, Qayyum N, Langton CM. Assessment of bone status using the contact ultrasound bone analyser. Arch Dis Child 1997; 76: 535-536.

53 Baroncelli Gl, Federico G, Bertelloni S, De TF, Cadossi R, Saggese G. Bone quality assessment by quantitative ultrasound of proximal phalanxes of the hand in healthy subjects aged 3-21 years. Pediatr Res 2001; 49: 713-718.

54 Zhu ZQ, Liu W, Xu CL, Han SM, Zu SY, Zhu GJ. Ultrasound bone densitometry of the calcaneus in healthy Chinese children and adolescents. Osteoporos Int 2007; 18: $533-541$.

55 Crofton PM, Evans N, Taylor MR, Holland CV. Serum CrossLaps: pediatric reference intervals from birth to 19 years of age. Clin Chem 2002; 48: 671-673.

56 Michelsen J, Wallaschofski H, Friedrich N, Spielhagen C, Rettig R, Ittermann T et al. Reference intervals for serum concentrations of three bone turnover markers for men and women. Bone 2013; 57: 399-404.

57 Yang L, Grey V. Pediatric reference intervals for bone markers. Clin Biochem 2006; 39: $561-568$.

58 Ambroszkiewicz J, Klemarczyk W, Gajewska J, Chelchowska M, Laskowska-Klita T. Serum concentration of biochemical bone turnover markers in vegetarian children. Adv Med Sci 2007; 52: 279-282.

59 Eliakim A, Nemet D, Wolach B. Quantitative ultrasound measurements of bone strength in obese children and adolescents. J Pediatr Endocrinol Metab 2001; 14: 159-164.

60 Kumar V, Venkataraghavan K, Krishnan R, Patil K, Munoli K, Karthik S. The relationship between dental age, bone age and chronological age in underweight children. J Pharm Bioallied Sci 2013; 5: S73-S79.

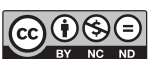

This work is licensed under a Creative Commons AttributionNonCommercial-NoDerivs 4.0 International License. The images or other third party material in this article are included in the article's Creative Commons license, unless indicated otherwise in the credit line; if the material is not included under the Creative Commons license, users will need to obtain permission from the license holder to reproduce the material. To view a copy of this license, visit http:// creativecommons.org/licenses/by-nc-nd/4.0/ 